\title{
A ESTRUTURA ORGANIZACIONAL DO MST: lógica política e lógica prática
}

\author{
Roberto de Sousa Miranda* \\ Luis Henrique Hermínio Cunha*
}

\begin{abstract}
Nosso objetivo é compreender as relações entre a base do Movimento dos Trabalhadores Rurais Sem Terra (MST) e suas lideranças, tomando como elemento de mediação a estrutura organizacional formalmente adotada em 2003. Para tanto, três chaves analíticas são utilizadas: Clastres, que explora a ideia de estrutura separada do corpo social; Leach, que opõe um modelo abstrato de organização às situações práticas observadas e interpretadas a partir da materialidade do comportamento dos assentados e acampados; o Neo-institucionalismo, que trata as instituições enquanto regras e normas que regulamentam a vida social. As análises foram baseadas em observações realizadas no XII Encontro Estadual do MST na Paraíba e nos assentamentos rurais José Antonio Eufrosino e Osiel Pereira, localizados no município de Campina Grande. Recusando as abordagens que tentam medir o grau de adoção dos modelos organizacionais formais pelos grupos sociais, tentamos revelar as incongruências produtoras das dinâmicas de reestruturação da organização do MST.

Palavras-Chave: MST. Estrutura Organizacional. Assentamentos Rurais. Paraíba.
\end{abstract}

\section{INTRODUÇÃO}

O Movimento dos Trabalhadores Rurais Sem Terra (MST) tem empreendido, ao longo de sua trajetória, transformações sistemáticas nas estruturas formais de tomada de decisão e de mobilização de seus membros, respondendo ou antecipando-se aos problemas e desafios com que se defronta, seja em sua ação política, seja nas atividades de mobilização da militância (Brenneisen, 2004; Ros, 2005; Fernandes, 2008), de organização dos acampamentos ou de implantação dos projetos de assentamento (Oliveira e Guerra, 2004; Miranda, 2007).

Este artigo não pretende apreender o sentido e o significado destas transformações nas estruturas formais de tomada de decisão do MST, mas analisar alguns aspectos das relações entre a

* Doutor em Ciências Sociais. Professor da Unidade Acadêmica de Ciências e Tecnologia Ambiental da Universidade Federal de Campina Grande.

Rua: Jairo Feitosa, s/n. Pereiros. Cep: 58840-000 - Pombal - Paraíba - Brasil. robertosmiranda@yahoo.com.br

** Doutor em Desenvolvimento Sustentável do Trópico Úmido. Professor adjunto I da Universidade Federal de Campina Grande. luishcunha@uol.com.br base do Movimento e suas lideranças e os processos de tomada de decisão em assentamentos rurais mediados pela nova estrutura organizacional formalmente adotada pelo MST em 2003 (Bernat, 2012).

A análise baseia-se em três chaves analíticas: a primeira, a partir de Clastres (2003), explora a ideia de estrutura separada do corpo social; a segunda, tomando Leach (1996) como referência, opõe um modelo abstrato de organização (o ideal organizacional que o grupo relembra em momentos especiais) às situações práticas observadas e interpretadas a partir da materialidade do comportamento de lideranças, assentados e acampados; e a terceira, ancorada no neoinstitucionalismo, nos permitirá analisar as instituições dos assentamentos rurais enquanto regras e normas que regulamentam a vida social das famílias assentadas (Miranda, 2007).

Partimos do pressuposto de que coexistem duas lógicas inerentes à ação do MST: uma lógica política, pela qual o Movimento se apresenta e se

${ }^{1}$ Embora o novo modelo organizacional seja nacional, ficou a critério dos Estados em que o MST está presente adotarem ou não a nova estrutura. 
representa e que orienta as estratégias de ação através das quais busca ganhar visibilidade; e uma lógica prática, adotada nas negociações com o poder público e a sociedade civil, nos esforços para desapropriação de áreas ocupadas ou viabilização de projetos de assentamento, e na gestão cotidiana de cooperativas, programas e projetos, que garante a legitimidade do movimento junto à base de famílias acampadas e assentadas.

A lógica política é construída em torno de ideais revolucionários, enquanto a lógica prática é elaborada em termos de resultados, conquistas, desempenho e eficiência. As duas lógicas são, ao mesmo tempo, contraditórias e complementares, sendo a primeira dominante naqueles momentos em que o MST celebra e reforça o ideal do grupo, enquanto a segunda predomina nas interações cotidianas e nas tomadas de decisão sobre os problemas enfrentados por acampados e assentados.

A coexistência dessas duas lógicas mostra, também, as tensões entre as bases e as lideranças do movimento. Entre 1989 e 1995, a implementação da organização coletiva dos assentados nos mais amplos aspectos, alicerçada na lógica política do movimento, enfrentou a resistência das famílias assentadas, que não aceitavam a coletivização do processo produtivo, como nos mostra Brenneissen (2004). As disputas, neste sentido, contribuíram para mudanças na organicidade e nas estratégias de ação do MST.

A base do MST não é homogênea, do ponto de vista das modalidades de trabalho (assalariados, arrendatários e trabalhadores volantes) e em relação às histórias e às trajetórias de vida das famílias (Brenneissen, 2004). Os elementos de identificação, que promovem a união entre famílias sem terra no período de acampamento, vão sendo dissolvidos com a criação do assentamento. Os acampados empreendem ações coletivas para adquirir um benefício comum, no caso a terra, guiados pela lógica política e prática do movimento. Adquirido o benefício, há uma desmobilização e, os agora assentados, tendem a reforçar a lógica prática.

Mediante esta compreensão, empreenderemos a análise das relações entre a base do movi- mento e suas lideranças nos espaços destinados à participação, tomada de decisão e relações mediadas (em seus elementos de legitimação, de conflito, de exercício de poder, de cooperação e de tomada de decisão) pela retórica e pelas práticas associadas à adoção do novo modelo organizacional. Baseamo-nos em observações etnográficas realizadas durante o XII Encontro Estadual do MST da Paraíba e em trabalho de campo ${ }^{2}$ nos assentamentos José Antônio Eufrosino e Osiel Pereira, localizados nos municípios de Campina Grande (PB) e Remígio(PB), respectivamente.

\section{ANOVA ESTRUTURA ORGANIZACIONAL DO MST}

O modelo organizacional implementado pelo MST a partir de 2003 é o resultado do aperfeiçoamento e da incorporação de formas de organização que já vinham sendo utilizadas anteriormente, juntamente com uma modificação significativa na estrutura formal anterior. Este modelo de organização é resultado de anos de debates e observações realizadas pelas lideranças e assessores do movimento.

Uma das origens da nova estrutura formal pode ser remetida ao debate sobre as agrovilas como modelo de organização para as moradias (MST, 2001). Os diferentes problemas enfrentados com a criação de agrovilas nos projetos de assentamento - principalmente nas regiões Centro-Oeste, Norte e Nordeste - levaram o movimento a desenvolver uma forma alternativa de disposição das casas dos assentados, chamados de núcleos de moradia e núcleos habitacionais.

Nos núcleos de moradia, as casas se localizavam no próprio lote, o que permitia a criação de animais sem incomodar os vizinhos. Nos núcleos habitacionais, as casas eram reunidas em grupos de 15 ou 25 famílias numa área coletiva. Na medi-

O trabalho de campo iniciou-se em março de 2005, com visitas periódicas. Em 2006, as visitas foram mais frequentes, intensificando-se quando fui todos os dias ao assentamento (por ser perto de Campina Grande), durante 20 dias consecutivos, no mês de julho do referido ano. E visitas complementares à direção do MST no Estado da Paraíba e acompanhamento de ocupações organizadas pelo movimento, entre os anos de 2007 e 2010. 
da em que foram sendo construídos esses núcleos, o MST introduziu os núcleos de base. As famílias que formavam um núcleo eram agrupadas em um núcleo de base. Quando o número de famílias por núcleo era maior que 30, criavam-se dois ou mais núcleos de base. Em cada núcleo de base eram escolhidos dois coordenadores, um homem e uma mulher, que também comporiam a coordenação do assentamento (MST, 2001).

Os núcleos de moradia, habitacional e de base foram importantes para a elaboração de modelos organizacionais do movimento em nível nacional. Por exemplo, os núcleos de famílias, comuns nos acampamentos e assentamentos do MST (nos Estados que adotaram o novo modelo de organização), e as brigadas são resultantes do aprimoramento dos núcleos de moradia, habitacional e de base.

No IV Congresso Nacional do MST, realizado em agosto de 2000 em Brasília, foi deliberada a construção de um novo modelo de organicidade para o movimento e a realização de uma ampla consulta às bases (assentados e acampados), chamada de mutirão, para que se posicionassem sobre a adoção do novo modelo nos Estados (Brenat, 2012). A estratégia do movimento era ampliar a participação das bases nos processos decisórios e manter a luta pela reforma agrária em evidência (MST, 2005b).

O Setor Nacional de Formação do MST identifica algumas das principais mudanças operadas pelo movimento em termos organizacionais (MST, 2005b):

a) a adoção da forma de organização das famílias em núcleos como alternativa à antiga direção coletiva, para ampliar a participação dos acampados e assentados nos processos de tomada de decisão;

b) ênfase na organização de base (organização horizontal), em detrimento do desenvolvimento das instâncias de representação em que os membros são indicados pela base (organização vertical) enquanto método de direção;

c) que a composição das direções estaduais tivesse como referência o número de famílias ligadas ao movimento (organizadas em brigadas compostas por 200 ou 500 famílias) e não o território;

d) a formação de um número maior de lideranças e o aumento no grau de participação dos membros do movimento, resultando na elevação do nível de consciência possibilitada pela criação dos núcleos de famílias;

e) o enfoque na mudança de hábitos e no caráter dos membros do movimento, que permitiria a superação do individualismo e do paternalismo, considerados vícios incompatíveis com a construção de uma sociedade socialista.

A nova organicidade deveria influenciar o processo de luta social para alcançar transformações políticas e, também, garantir, na medida do possível, direitos iguais para homens e mulheres. Mas, para que isso ocorresse, seria preciso: clareza para onde se quer ir; capacidade de tomar iniciativas e agir organizadamente; estrutura material própria; uma mística de animação, estímulo e conviç̧ão de que só a luta traz as mudanças desejadas; e planejar todas as atividades com antecedência (MST, 2005b).

O entendimento deste novo modelo de organização do MST passa, necessariamente, pela compreensão do funcionamento das brigadas, peças chave no processo de tomada de decisões em nível estadual.

\section{O funcionamento das brigadas}

As brigadas (com 200 ou 500 famílias) foram criadas para substituir as grandes regionais, permitir uma maior participação de homens e mulheres e facilitar a multiplicação de lideranças (MST, 2005a). Cada estado organiza suas brigadas de acordo com sua realidade geográfica e de construção do MST através da participação da militância.

A denominação brigada remeteria a partes de uma organização que desenvolvem tarefas diferentes, mas possuem um mesmo objetivo. As brigadas são formadas por:

a) Núcleos de Base, compostos por mais ou menos 10 famílias e coordenados por um homem e uma 
mulher. As famílias devem se reunir, pelo menos, duas vezes ao mês, para discutir os problemas locais, planejar o trabalho voluntário, recolher a contribuição para a marcha e escolher os representantes que irão participar das viagens, dos cursos e encontros, além de organizarem atividades coletivas como o mutirão e a troca de dias de trabalho. Os coordenadores anotam as opiniões dos participantes, visitam as famílias e encaminham os problemas;

b) Setores (de frente de massa, de produção, de educação, de formação, de saúde, de gênero, de comunicação e de cultura) - cada setor possui dez representantes, cada representante é responsável por três ou cinco núcleos de famílias; já os setores estaduais são compostos por um representante de cada brigada. Também fazem parte dos setores a secretaria, a equipe de finanças, a equipe de disciplina e a equipe de direitos humanos. Têm o objetivo de orientar e ajudar os membros nas orientações dadas pelo movimento. O setor da frente de massas cuida das ocupações e das mobilizações. Já o setor de educação deve ser composto por professores, pais e estudantes, que se encarregam de pensar e encaminhar as questões referentes ao ensino nas escolas e a alfabetização de adultos. O setor de formação, composto por homens e mulheres, é responsável pelos cursos e pela qualidade das discussões dentro do MST. O setor de cultura é responsável pela construção de uma nova cultura, baseada na formação de homens e mulheres possuidores de valores humanistas e com consciência de classe;

c) Direção Coletiva é composta por um representante a cada cinco núcleos. Uma brigada formada por 500 famílias tem, por exemplo, 10 dirigentes, que devem ser homens e mulheres. Da direção participam, ainda, dois representantes de cada setor, para que se mantenha a unidade entre todos eles. Os dirigentes são incumbidos de repassar os informes aos demais coordenadores de núcleo;

d) Coordenação da Brigada é composta por todas as pessoas responsáveis por alguma função, seja nos núcleos ou nos setores, e pela direção, in- cluindo, assim, dois coordenadores de cada núcleo, 10 representantes de cada setor e mais 10 membros da direção, totalizando mais ou menos 180 lideranças em cada brigada. E tem como objetivo planejar as atividades para adultos, jovens e crianças, fazer com que os lotes e os créditos cumpram sua função social: desenvolver econômica, política, social, cultural e ambientalmente os assentamentos (MST, 2005a).

As transformações organizacionais apresentadas representaram uma mudança significativa da relação entre as lideranças e a base do movimento, pois os Estados que adotaram esse novo modelo substituíram as antigas regionais por estruturas descentralizadas, que possibilitaram o aumento da participação e, assim, ampliaram o número de lideranças (Bernat, 2012).

\section{ESTRUTURA DE PODER SEPARADADO CORPOSOCIAL}

Clastres (2003) defende a tese de que a ausência do Estado nas sociedades primitivas não é resultante de um baixo nível de desenvolvimento, mas de uma postura de recusa ao Estado, enquanto poder coercitivo separado da sociedade. O chefe ${ }^{3}$ primitivo não era um comandante, ${ }^{4} \mathrm{o}$ poder político era exterior a ele, sua função era, somente, de resolver os conflitos que surgissem entre as pessoas, as famílias e as linhagens, e para isso dispunha apenas do prestígio para restabelecer a ordem.

Nestes termos, o aparelho estatal não poderia derivar da chefia primitiva porque: (a) o espaço da chefia primitiva não era um lugar de poder; (b) não havia, nas sociedades primitivas, um vazio que o Estado pudesse preencher e (c) a indivisibilidade do poder impossibilitaria a configuração de uma

${ }^{3}$ A figura que serviu de inspiração a Clastres (2003) foi a do chefe indígena (figura certamente genérica), autoridade que não detém poder algum, prisioneiro do grupo. Mesmo sendo beneficiado com alguns privilégios, como a poliginia, o chefe estava submetido a uma série de obrigações que pressupõem certas habilidades, dentre as quais, as mais importantes são a generosidade e o dom da oratória.

${ }^{4}$ Somente em períodos de guerras e em expedições militares o chefe podia exercer um mínimo de autoridade, que se fundava na sua competência de guerrear (Clastres, 2003). 
estrutura política separada do corpo social. Há, portanto, um vínculo inescapável, para Clastres (2003), entre a existência do Estado e a divisão entre os que mandam e os que obedecem.

Embora Clastres (2003) tenha focalizado as sociedades primitivas, coloca questões importantes para os vínculos existentes entre estruturas formais de organização para a tomada de decisões e o exercício de poder. No caso do MST, esta questão é especialmente relevante, na medida em que sua organicidade se fundamenta no pressuposto de um poder indiviso, que é patrimônio de todas as famílias ligadas ao movimento. Na prática, porém, como veremos, o exercício da liderança no MST se dá associado ao exercício de poder por indivíduos ou grupos de indivíduos. Não se trata, pois, de uma liderança que se exerce unicamente pelo prestígio ou pelo dom retórico.

\section{ESTRUTURA SOCIAL, RITUAL E EXERCÍCIO DE PODER}

$\mathrm{Na}$ antropologia, o conceito de estrutura social remete ao sistema formal de relações entre pessoas e grupos de pessoas dentro de um sistema social. Segundo Leach (1996), porém, os padrões formais dos sistemas estruturais (definidos em termos tradicional e místico) não oferecem interpretações inequívocas da realidade do mundo social. A ambiguidade das categorias sociais é fundamental para a materialização das estruturas formais de organização (Sigaud, 1996).

Há um contraste entre estrutura social ideal e as práticas concretas dos atores sociais, de acordo com os interesses diferentes e conflitantes. Os lugares de autoridade formal convivem com outros lugares informais de exercício de poder. Ou seja, a estrutura social, em situações práticas, é um conjunto de ideias sobre a distribuição do poder entre pessoas e grupos de pessoas. Os indivíduos alimentam ideias contraditórias e incongruentes sobre o sistema social, e fazem isso sem nenhuma dificuldade, porque a forma da estrutura social é cultural e sua expressão é ritual (Leach, 1996).
Quando se descreve um sistema social, descreve-se um modelo da realidade, no qual as distintas partes do modelo compóem um todo coerente e em equilíbrio, que só pode ser representado como um sistema de equilíbrio enquanto modelo. Pois a realidade social não forma uma totalidade coerente, pelo contrário, é, em grande parte, cheia de incongruências. Por outro lado, a descrição da estrutura social fornece um modelo idealizado, que mostra as relações de status existentes entre os grupos constituintes do sistema total e entre as pessoas que formam os grupos particulares (Leach, 1996).

A partir do conceito de ritual, Leach (1996) observa as incoerências existentes entre a estrutura formal e as práticas costumeiras das pessoas de um dado sistema social. O ritual é entendido como a expressão do status do indivíduo enquanto pessoa social do sistema estrutural do qual faz parte. Por exemplo, os procedimentos cotidianos dos Kachins, ${ }^{5}$ como limpar o terreno, plantar e capinar são todos padronizados por convenções formais, intercaladas com adornos e ornatos que, tecnicamente, são supérfluos, mas, necessários para determinar o desempenho kachin, e não outro.

Quando as pessoas realizam seus afazeres cotidianos, atividades para satisfazer suas necessidades básicas, as relações formalmente estruturadas podem ser totalmente desprezadas. Porém, para evitar a desordem, os indivíduos que compõem uma sociedade devem ser lembrados, ao menos simbolicamente, da ordem básica que guia suas atividades sociais. Essa é a função dos rituais nos grupos sociais como um todo, tornar “[...] momentaneamente explícito aquilo que de outro modo é ficção” (Leach, 1996, p.78).

É o ritual que expressa o status do indivíduo enquanto pessoa social no sistema ao qual está ligado, em referência à estrutura social formal. Durante o ritual, os status individuais são relembrados e reforçados. O ritual é uma "declaração simbólica que 'diz' alguma coisa sobre os indivíduos envolvidos na ação” (Leach, 1996, p. 76). ${ }^{5}$ Leach (1996) denomina de Kachin toda a população que
habita a Região das Colinas Kachin no nordeste da Birmânia. 


\section{O XII ENCONTRO ESTADUAL DO MST DA PARAÍBA}

Ao contrário das reuniões de brigada, em que todas as famílias ligadas ao MST são convidadas a participar, a participação no Encontro Estadual é mais restrita. A disciplina e a mística, $c i$ mento ideológico do movimento (Turatti, 2005), eram os dois elementos que se destacavam durante a realização do XII Encontro Estadual do MST da Paraíba, realizado nos dias 15, 16 e 17 de dezembro de 2005, no ginásio de esportes do Campus I da Universidade Federal de Campina Grande, na cidade de Campina Grande.

A agenda do Encontro trazia temas nacionais deliberados no IV Congresso Nacional do MST, em 2000: avaliação da nova organicidade e defesa do rio São Francisco e da Amazônia; avaliação da Marcha realizada em maio de 2005; e questões que estiveram presentes no $\mathrm{V}$ Congresso Nacional do MST, em 2007: combate às empresas transnacionais que queriam controlar a produção de sementes e defesa das sementes nativas e crioulas. As questões locais diziam respeito: às ações de expansão do movimento no Estado, à falta de assistência técnica e às ameaças aos militantes.

Parte da agenda do Encontro já tinha sido discutida nas reuniões das brigadas e dos setores, tais como: a avaliação da nova organicidade e da Marcha, a defesa das sementes crioulas e as ameaças às lideranças do movimento. A direção do MST, portanto, articulou, antecipadamente, as questões centrais que foram decididas no Encontro, e deulhes um respaldo maior quando as associou às palavras de ordem, às palestras, à mística e à própria organização dos espaços usados no Encontro.

Os sem-terra ficaram alojados nas salas de um bloco de aulas e nas arquibancadas do próprio ginásio. As refeições foram feitas numa cozinharefeitório improvisada. Assentados, acampados e demais participantes faziam as refeições nos degraus de um corredor coberto que dá acesso à biblioteca ou em qualquer lugar, próximo à cozinha, em que pudessem se proteger do sol. Percebia-se uma grande solidariedade entre todos: os que pre- paravam os alimentos e os que se serviam.

O ginásio de esportes, lugar de realização das reuniões, estava decorado com símbolos que remetiam à identidade do MST (enxadas, facões, foices etc.). Na quadra, duas fileiras de cadeiras com uma mesa à frente (que lembrava muito um altar de igreja), ornamentada com uma toalha branca coberta por uma toalha vermelha e pela bandeira do movimento. À esquerda do altar tinha um pedestal com um microfone e caixas de som nos dois lados. Nas arquibancadas ao redor da quadra, estavam guardados bolsas, colchões e utensílios de uso pessoal dos participantes do encontro.

As atividades foram divididas em dois períodos principais, manhã e tarde, enquanto a noite era dedicada ao lazer dirigido (ver filmes e músicas que fortalecessem a identidade de Sem-Terra, por exemplo). As reuniões eram sempre muito organizadas e, depois que as atividades eram iniciadas, os portões do ginásio eram fechados e só as pessoas da organização tinham livre acesso.

No início das atividades de cada período eram realizadas místicas. As místicas consistiam em apresentações (artísticas) acompanhadas de músicas, textos lidos e/ou a fala de palavras de ordens (reforma agrária já, por exemplo), realizadas pelos próprios membros do movimento (assentados e acampados). A mística era organizada pelo setor ou grupo responsável pelas atividades do período.

O momento da apresentação da mística era um dos mais emocionantes do encontro. Nas místicas, os participantes pareciam estar em êxtase, pulavam, cantavam, gritavam, aplaudiam e alguns lacrimejavam. Após a mística, iniciavam-se as palestras e os debates, algumas falas eram marcadas pelo grito de palavras de ordem ("reforma agrária já", por exemplo), repetidas e, às vezes, aplaudidas pela plateia.

Outro momento em que ficou perceptível a afirmação da identidade e da organicidade do MST foi quando todos os presentes no ginásio receberam bonés vermelhos com o símbolo do movimento e foram convidados a usá-los naquele momento. Das arquibancadas, lugar em que nos encontrávamos, tinha-se a impressão, por alguns segundos, 
que todos eram iguais e parte de um só corpo.

A mística, como outros rituais encenados pelos membros do MST, constitui-se em elementos importantes para se apreender as relações entre as lideranças e as bases do movimento. No ideal do grupo, são relações equilibradas e harmoniosas. A separação da estrutura formal de tomada de decisões do corpo social é compensada, nestes momentos, pela referência à participação da base nas decisões mais importantes tomadas no âmbito dos Encontros Estaduais e Nacionais.

Os Encontros Estaduais do MST representaram e representam, assim, momentos em que o modelo organizacional ideal se materializa e todos os assentados, acampados e lideranças relembram os objetivos e maneiras de continuar a luta pela terra e agilizar a reforma da estrutura agrária brasileira. Além disso, representam momentos que os demais participantes (políticos, professores, universitários e demais convidados) apreendem a lógica política (ideológica) do movimento.

Já a relação entre a base e a liderança do MST pôde ser observada de duas formas no Encontro Estadual. A primeira está relacionada à limitação da participação, apenas uma parcela da base estava presente, porém a nova organicidade possibilitou uma comunicação maior com os demais membros do movimento, porque as brigadas realizaram um papel de divulgação das deliberações. A segunda se refere aos núcleos de família, que possibilitaram o aumento do número de lideranças e a descentralização organizacional ao indicarem participantes para encontros e reuniões.

\section{INSTITUIÇÕES E PROCESSOS DE TOMADA DE DECISÃO NOS ASSENTAMENTOS}

As instituições possibilitam a redução das incertezas (Dimaggio e Powell, 1999; Hall e Taylor, 1999; Peters, 2003; Romero, 1999) ao fornecerem regras e normas que regulam os comportamentos individuais e institucionalizam o contexto no qual se darão as relações sociais, políticas e econômicas (Northe, 1990). A importância das instituições na vida social tem sido enfatizada por diferentes autores associados ao neo-institucionalismo e é um tema recorrente nos debates relacionados aos processos constitutivos dos assentamentos de reforma agrária no Brasil.

As instituições dos assentamentos rurais desempenham um importante papel no processo de ordenação e estruturação social e produtiva. Além disso, possibilitam a superação dos conflitos vividos pelas famílias assentadas, especialmente nos primeiros anos, através da (re)definição de regras e normas que inibam comportamentos oportunistas e regulem a vida social, política e econômica (Miranda, 2007). O processo de reestruturação está relacionado à modificação dos arranjos institucionais existentes ou criação de novas instituições sociais.

No caso dos assentamentos rurais, as associações se constituem em instituições predominantes, “[...] pelo simples fato de que são uma espécie de 'exigência' do Estado [...]” (Leite, 2004, p. 113). Nos assentamentos em que não existem associações, outras instituições formais, como as cooperativas, constituem-se em arranjos institucionais responsáveis pela superação dos dilemas de ação coletiva $^{6}$ e redução dos conflitos relacionados ao uso e acesso aos recursos naturais.

Os assentamentos José Antonio Eufrosino e Osiel Pereira constituíram bons exemplos de implementação dos Núcleos de Família, visto que possuíam características distintas, e articulação entre arranjos institucionais complementares. No primeiro, as famílias construíram suas casas nos lotes, portanto, a distância torna-se um empecilho à realização de assembleias e reuniões, enquanto, no segundo, as casas foram erguidas em agrovilas (três no total), o que facilita a mobilização das famílias.

6 São contradições entre a racionalidade individual e a racionalidade coletiva que perpassam a aquisição de benefícios coletivos, em que "[...] cada membro preferiria que os outros pagassem todo o custo sozinhos [...] “ (Olson, 1999, p. 33). A resolução de dilemas sociais pode ocorrer através da ação de um interventor externo que ofereça incentivos ou imponha sanções (Olson, 1999), ou através da reciprocidade e da confiança existente entre os indivíduos (Ostrom, 1998). 


\section{Assentamento José Antonio Eufrosino}

As instituições do assentamento José Antônio Eufrosino ${ }^{7}$ foram sendo criadas de acordo com as exigências formais do Estado e as necessidades de redefinição dos arranjos institucionais que visavam à superação dos dilemas sociais inerentes às ações coletivas empreendidas pelas famílias para executar e implementar políticas governamentais encaminhadas pelos representantes do Instituto Nacional deColonização e Reforma Agrária (INCRA). $\mathrm{O}$ assentamento possuía duas instituições principais: a associação e os núcleos de família.

Para que as famílias tivessem acesso ao crédito de fomento, às $20 \mathrm{~h}$ do dia 18 de dezembro de 2001, foi criada a Associação dos Trabalhadores Rurais do Assentamento Bom Jesus (ATRABJ). De acordo com a Ata de Fundação, 70 pessoas estavam presentes na assembleia de criação, embora existissem 200 famílias morando no assentamento. A assembleia foi coordenada pelo senhor José Avelino da Silva e secretariada pelo senhor Laudemir Rodrigues de Lucena, ambos assentados.

A criação da associação foi marcada por desencontros. Ao mesmo tempo em que o INCRA orientou a formação da associação, para que as famílias recebessem o crédito de fomento, já havia sido iniciada a elaboração do Plano de Desenvolvimento do Assentamento (PDA), com o nome de José Antônio Eufrosino, ${ }^{8}$ e os assentados não sabiam que a associação deveria ter o mesmo nome do assentamento. Em virtude do acontecido, o nome da associação teve de ser modificado para

${ }^{7} \mathrm{O}$ assentamento José Antônio Eufrosino, localizado na porção semiárida do município de Campina Grande (PB), foi criado no ano de 2001, mediante a desapropriação das fazendas Monte Alegre, Castelo, Bonfim e Logradouro, ofertadas ao Instituto Nacional de Colonização e Reforma Agrária (INCRA) pelo antigo proprietário. O processo de ocupação foi coordenado pelo MST e pela Federação Nacional dos Trabalhadores na Agricultura (FETAG)

${ }^{8} \mathrm{O}$ assentamento recebeu esse nome porque as famílias ligadas à FETAG anteciparam-se e, ao entrarem em contato com a Associação Técnico-Científica Ernesto Luiz de Oliveira Júnior (ATECEL) e o INCRA, no início da elaboração do PDA, disseram que o Assentamento se chamaria José Antônio Eufrosino, em homenagem ao fundador do Sindicato dos Trabalhadores Rurais de Campina Grande. Fato que contrariou a maioria das famílias assentadas (ligadas ao MST) que queriam que o assentamento se chamasse Bom Jesus.
Associação dos Trabalhadores Rurais do Assentamento José Antônio Eufrosino (ATRAJAE). ${ }^{9}$

A administração da primeira diretoria da associação adotou práticas ilícitas para eleger-se e manter-se à frente da instituição. Dentre elas, destaca-se a rasura da Ata de Fundação, para que um assentado ligado ao último arrendatário de uma das fazendas, que tinha interesse em manter seus animais nos pastos da área reformada, fosse o presidente. Concomitantemente, lideranças do MST intensificaram a presença no assentamento, na tentativa de implementar mecanismos de regulação do acesso e uso dos recursos naturais, de modo que as ações predatórias fossem coibidas.

Depois da descoberta dessas fraudes, a associação passou a ser gerida pelos assentados próximos ao MST, e o número de famílias no assentamento foi sendo reduzido até chegar a 100. A mudança de gestão e a formalização de um arranjo institucional, que se preocupou com a regulamentação dos deveres e obrigações dos assentados, levaram as famílias ligadas à FETAG (17 famílias) a formarem outra associação. O Presidente da nova associação residia na cidade, aparecendo no assentamento nos finais de semana e feriados. Nesse período, a instância máxima decisória era a Assembleia Geral, com a presença dos membros das duas associações.

Em 2006, a associação ligada à FETAG foi extinta e seus associados migraram para a ATRAJAE, ligada ao MST. O principal motivo para a extinção fora a ausência de ações que possibilitassem a estabilização das famílias no assentamento, principalmente créditos oficiais. Até então, as principais políticas governamentais destinadas aos assentados, o parcelamento e o recebimento do crédito para a execução das casas, foram executadas e implementadas pela ATRAJAE.

A organização do assentamento, contudo, não se resumia à associação. A organização interna era,

A diretoria da associação é formada pelo Presidente, VicePresidente, Tesoureiro, Vice-Tesoureiro, Secretário, ViceSecretário e 3 membros que compõem o Conselho Fiscal. O mandato de cada diretoria tem a duração de 2 anos, cabendo aos membros da direção se candidatarem, ilimitadamente, à reeleição. A filiação é aberta a todos os assentados maiores de idade. 
na verdade, articulada por quatro núcleos de família que correspondem, geograficamente, a cada uma das antigas fazendas Logradouro, Bonfim, Castelo e Monte Alegre. A nucleação foi iniciada em 2003, por iniciativa de lideranças estaduais e regionais do MST que realizaram um trabalho de formação e orientação com as famílias do assentamento.

No assentamento José Antônio Eufrosino, cada um dos quatro núcleos de família era composto por 25 famílias, sendo dois coordenadores em cada núcleo (um homem e uma mulher), que se reuniam uma ou duas vezes ao mês, para discutir os problemas locais; recolher contribuições, quando necessário, escolher os assentados que irão participar de cursos e encontros; e para organizar trabalhos coletivos. Além disso, os coordenadores dos núcleos, com os representantes dos setores, fiscalizavam o cumprimento das regras de uso e acesso aos recursos naturais e coletivos.

O processo de tomada de decisão no assentamento ocorria em duas esferas distintas, porém complementares: nas assembleias da associação e nas reuniões dos núcleos de família (Monte Alegre, Castelo, Bonfim e Logradouro). Aliás, as principais questões que envolviam os assentados começaram a ser debatidas nos núcleos de família, que encaminhavam os resultados às assembleias da associação, para que, assim, as deliberações fossem formalizadas.

Era nos núcleos que as questões do assentamento começavam a ser debatidas. A implementação desse arranjo institucional reduziu os custos sociais, ao descentralizar as discussões e os processos de tomada de decisão; facilitou e estimulou a participação de um número maior de assentados nas reunióes e assembleias realizadas; reduziu as incertezas que cercavam a regulação do acesso e uso dos recursos naturais ao institucionalizar um grupo de fiscalização.

Com a criação dos núcleos de família, a associação passou a exercer, principalmente, a interlocução externa, e as assembleias (ordinárias e extraordinárias) passaram a ser menos frequentes e a ter caráter de encaminhamento. A pauta era previamente debatida nos núcleos, e as decisões formalizadas e encaminhadas nas assembleias. Caso alguma questão envolvesse, apenas, as famílias de um núcleo, este teria autonomia para tomar as decisões necessárias à resolução dos conflitos e problemas:

[...] a assembleia para nós tem o caráter de encaminhamento, não de discussão, porque senão não teria sentido em ter grupo [núcleo] de família, se reunir por grupos para poder discutir as coisas melhor [...]. A gente acredita que as coisas têm que ser discutidas nos grupos e que esses grupos repitam isso na assembleia, para que a assembleia seja a prova disto, aonde vai ter a opinião dos quatro grupos e aí vai passar por uma votação geral, aonde a gente vai chegar a aprovar ou não (Assentado do núcleo Castelo, membro da direção estadual do MST).

\section{Assentamento Osiel Pereira}

O assentamento Osiel Pereira ${ }^{10}$ sofreu muitas modificações institucionais ao longo de sua história, tanto em termos estruturais como em termos institucionais. Aqui nos deteremos, especialmente, aos aspectos institucionais. As transformações e redefinições dos arranjos institucionais estão relacionadas aos conflitos que levaram à divisão do assentamento e à criação do Projeto de Assentamento Queimadas. ${ }^{11}$

Com a criação do assentamento, em 1999, as famílias formaram a Associação dos Trabalhadores Rurais do Assentamento Osiel Pereira (ATRAOP), que representava 150 famílias. O processo de criação da associação, assim como em muitos assentamentos do país, contou com o apoio de representantes do Sindicato, do INCRA e do MST. As primeiras ações apoiadas ou

${ }^{10} \mathrm{O}$ assentamento Osiel Pereira, localizado na região semiárida do município de Remígio, foi criado em 1998. Entretanto, no ano de 2002, devido a conflitos internos, foi dividido, dando origem a outro assentamento (Queimadas).

11 Entre 1999 e 2002, eram constantes as disputas entre as famílias assentadas pelo acesso e uso de recursos naturais (água e madeira); o conflito teve seu ápice quando os assentados começaram a trocar tiros e um assentado foi assassinado. Após os acontecidos, o INCRA optou pela divisão do assentamento. A divisão do projeto de assentamento Osiel Pereira, que deu origem ao projeto de assentamento Queimadas, constitui-se, até 2007, no único caso do Estado da Paraíba (Miranda, 2007). 
coordenadas pela associação foram a elaboração do PDA e a ordenação social e espacial da área.

A impossibilidade de superação dos conflitos contribuiu para a criação da Cooperativa Agropecuária do Assentamento Osiel Pereira Ltda. (COOPAP), ${ }^{12}$ em 2002. A cooperativa significou o estabelecimento de arranjos institucionais pouco conhecidos pelos assentados, que tinham experiência em empreender ações coletivas e em se organizarem através de associações. Devido a esses fatores, a COOPAP é administrada a partir da lógica de uma associação. A preocupação principal dos membros da diretoria era a aquisição de benefícios coletivos que melhorassem a infraestrutura do assentamento.

A primeira tarefa desempenhada pela COOPAP foi representar os assentados ligados ao MST na divisão do assentamento, que herdou o nome e a estrutura administrativa do assentamento Osiel Pereira. Em decorrência disso, os créditos que já haviam sido disponibilizados para as 150 famílias assentadas (crédito para a construção das casas e linhas de financiamento para as famílias) foram creditados nas contas da cooperativa. Para o INCRA na Paraíba, a criação da COOPAP representou, apenas, a substituição de um arranjo institucional por outro.

A organização do assentamento não se

${ }^{12} \mathrm{O}$ corpo diretivo da COOPAP é composto pelo Presidente, Vice-Presidente, Tesoureiro, Vice-Tesoureiro, Secretário, Vice-Secretário e 3 (três) membros que compõem o Conselho Fiscal. Cada diretoria tem um mandato de 2 (dois) anos, podendo reeleger-se ilimitadamente. A filiação é aberta a todos os assentados maiores de idade.
Os núcleos de família foram importantes para a superação de dilemas sociais relativos à pesca e à extração de madeira, que surgiram após a divisão do assentamento, porque as famílias estavam organizadas a partir de relações sociais já estabelecidas. De 2002 a 2004, as reuniões dos núcleos foram frequentes e as decisões tomadas eram encaminhadas à COOPAP, que, em assembleia, formalizava as decisões. Contudo, a partir de 2005, os núcleos perderam espaço nos processos de tomada de decisão.

Os núcleos Cajá e Pia deixaram de realizar reuniões, porque as famílias não moravam na mesma agrovila e seria custoso realizar duas reuniões, assim, optou-se pela realização de uma única reunião. No caso do núcleo Lagoa de Jogo, havia diferenças e confusões. Como as famílias moravam na mesma agrovila, as reuniões são mais frequentes e a participação era expressiva. Apesar disso, em muitos casos, os assentados não conseguiam diferenciar quando era uma assembleia da cooperativa, somente com os assentados da agrovila de Lagoa de Jogo ou do núcleo Lagoa de Jogo.

Os núcleos de família não vinham ocupando um papel tão importante quanto o percebido no assentamento José Antônio Eufrosino, em queas casas são nos lotes. Como as famílias optaram por agrovilas, os custos para a realização de assembleias da cooperativa não eram tão grandes e a mobilização dos assentados demanda menos tempo. Por serem duas agrovilas, separadas por $6 \mathrm{~km}$, as assembleias passaram a acontecer alternadamente em cada uma delas.

As assembleias da cooperativa aconteciam mensalmente, durante os anos de 2002 e 2003, e todos os assuntos discutidos nas assembleias eram registradas em Ata. Após este período, tornaramse menos frequentes, ocorrendo, apenas, quando havia liberação de crédito, a necessidade de superação de conflitos ambientais e sociais e a visita de técnicos do INCRA. E as assembleias que vinham acontecendo não contavam com a participação de muitos assentados.

As famílias do núcleo Lagoa de Jogo tinham participado mais das assembleias da cooperativa para cobrar a regulação do acesso e uso dos recursos 
naturais. Como a área de reserva, a área coletiva e a maior parte dos recursos hídricos e dos lotes localizam-se em Lagoa de Jogo, as famílias dessa área reclamaram que estavam fiscalizando, sozinhas, as áreas de reserva, e que as famílias da outra agrovila não ajudavam na limpeza dos barreiros e do açude.

Os problemas enfrentados pelas famílias da agrovila de Lagoa de Jogo representam casos em que a utilização dos recursos naturais é coletiva, mas a repartição dos custos sociais é desigual. Todos utilizam a água, a área de reserva e a área coletiva, porém nem todos estão interessados em participar das ações coletivas que visavam à regulação e manutenção desses benefícios. Isso ocorre porque as instituições sociais do assentamento não permitiam o estabelecimento de regras e normas que possibilitassem a superação dos dilemas sociais.

O processo de tomada de decisão no assentamento ocorria em três esferas: nas assembleias da cooperativa, nas reuniões das agrovilas coordenadas por membros da diretoria da cooperativa e nos núcleos de família. Para facilitar e agilizar a tomada de decisão, a cooperativa, muitas vezes, realizava reuniões em cada uma das agrovilas para que houvesse um debate inicial e uma assembleia geral para formalizar e encaminhar as decisões. Os núcleos de família estavam perdendo espaço, principalmente os de Cajá e Pia, devido à organização espacial adotada no assentamento.

\section{CONSIDERAÇÕES FINAIS}

Nos assentamentos José Antônio Eufrosino e Osiel Pereira podemos perceber que um mesmo arranjo institucional (núcleos de família) produz resultados distintos, devido às especificidades locais, e são redefinidos ou destituídos de acordo com as necessidades das famílias assentadas. Com isso, queremos ressaltar que instituições possibilitam a formação de novas instituições e as experiências associativas adquiridas pelos assentados possibilitam a resolução de conflitos futuros.

Tendo como referência as formas de articulação e mediação apresentadas, podemos visualizar a materialização da lógica política, característica dos Encontros Estaduais, e da lógica prática, presente no cotidiano das famílias, que se organizam em núcleos e possuem certa autonomia para se organizarem em um modelo organizacional que representa a capacidade do movimento de se rearticular e se reorganizar constantemente, de modo que os ideais se mantenham vivos.

O novo modelo organizacional descentraliza os espaços de tomada de decisão, ao criar os núcleos de família e as brigadas, sem desarticular as demais partes orgânicas que constituem o movimento e sem fragmentar a estrutura de poder indivisa que permeia as mediações entre a base e as lideranças, o que permite o aumento da capacidade de comunicação e articulação do MST.

Embora o MST apresente uma lógica política orientada pela bandeira da reforma agrária e de uma sociedade socialista, os espaços constituintes da estrutura organizacional do movimento são permeados por estruturas paralelas e arranjos institucionais que refletem uma lógica prática, em que, muitas vezes, os ideais do movimento não são mencionados e os conflitos de interesse e as desigualdades no exercício de poder podem ser observados.

Apesar disso, a dissociação entre estrutura de poder e corpo social não se concretiza definitivamente, e as mudanças no modelo formal de organização social podem ser interpretadas como um esforço do movimento para criar dificuldades, ainda que simbólicas, a esta separação, que poderia comprometer a legitimidade das ações de lutas pela terra empreendidas.

A mística, a bandeira, os hinos, os bonés e as ferramentas de trabalho dão sentido às práticas dos sem-terra (Cruz, 2010) e funcionam como um elo entre o mundo real e o mundo ideal, em que se apresenta a identidade do movimento, sempre em construção. Aos aspectos simbólicos se atribui a grande força que leva os membros do movimento a lutar por objetivos imediatos, superar derrotas, aprender com elas e, principalmente, persistir na luta (MST, 2001). Aceito em 24 de setembro de 2012 


\section{REFERÊNCIAS}

BERNANT, I. G. Um no jeito de organizar. A nova organicidade em/do movimento; luta pela terra, luta na terra e identidade sem terra na área de influência da Brigada Salvador Allende-MST (Paraná). 2012. 293f. Tese (Doutorado em História) - Departamento de História, Universitat de Lleida, Lleida, 2012.

BRENNEISEN, E. O MST e os assentamentos rurais no Oeste do Paraná: encontros e desencontros na luta pela terra. Revista Estudo Sociedade e Agricultura, Rio de Janeiro, v. 12 , n. 1, p. 128-163, jan. 2004.

CLASTRES, P. A sociedade contra o Estado. São Paulo: Cosac \& Naify, 2003.

CRUZ, F. S. Do essencialismo ao não essencialismo? Reflexões sobre a identidade cultural do MST. Revista Lua Nova, São Paulo, n. 80, p. 181-201, maio/ago. 2010.

DIMAGGIO, P. J.; POWELL, W. W. Introdução. In: POWELL, W. W.; DIMAGGIO, P. J. (Comp.). El nuevo institucionalismo en el análisis organizacional. México: Fondo de Cultura Económica, 1999, p. 33-75.

FERNANDES, B. M. 27 anos do MST em luta pela terra In: FERRANTE, V. L. S. B. et al. Reforma agrária e desenvolvimento: desafios e rumos da política de assentamentos rurais. Brasília: MDA, 2008. p. 27-52.

HALL, P. A.; TAYLOR, R. C. R. As três versões do neoinstitucionalismo. Revista Lua Nova, São Paulo, n. 58, p. 194-223, 2003.

LEACH, E. R. Sistemas políticos da Alta Birmânia. São Paulo: EDUSP, 1996.

LEITE, S. et al. Impactos dos assentamentos: um estudo sobre o meio rural brasileiro. São Paulo: EDUNESP, 2004.

MIRANDA, R. S. Desempenho institucional e a superação dos dilemas sociais em assentamentos do semi-árido paraibano. 2007. 145p. Dissertação (Mestrado em Sociologia) - Centro de Humanidades, Universidade Federal de Campina Grande, Campina Grande, 2007.
MST. Construindo o caminho. São Paulo: Secretaria Nacional, 2001.

MST. O funcionamento das Brigadas do MST. São Paulo: Setor de formação do MST, 2005a.

MST. Método de trabalho e organização popular. São Paulo: Setor de formação do MST, 2005b.

NORTH, D. C. Institutions, institutional change and economic performance. Cambridge: Cambridge University Press, 1990

OLIVEIRA, I. C.; GUERRA, L. D. Os significados da representação política nos discursos de militantes e líderes do MST: aspectos observados no caso do sul da Bahia. Revista Raízes, Campina Grande, v. 23, n. 1 e 2, p. 127-139, jan./dez. 2004.

OLSON, M. Lógica da ação coletiva. São Paulo: EDUSP, 1999.

OSTROM, E. A behavioral approach to the rational choice theory of collective action. American Political Science Review, Washington, v. 92, n. 01, p. 1-21, Mar. 1998.

PETERS, B. G. El nuevo institucionalismo: teoria institucional en ciencia política. Barcelona: Gedisa, 2003.

ROMERO, J. J. Los nuevos institucionalismos: sus diferencias, sus cercanías. In: POWELL, W. W.; DIMAGGIO, P. J. (Comp.). El nuevo institucionalismo en el análisis organizacional. México: Fondo de Cultura Econômica, 1999, p. 7-29

ROS, C. A. O MST, as instâncias do Estado para o tratamento da questão agrária e a constituição dos assentamentos rurais. In: MOREIRA, R. J. (Org.). Identidades sociais: ruralidades no Brasil contemporâneo. Rio de Janeiro: DP\&A, 2005. p. 127-174.

SIGAUD, L. Apresentação. In: LEACH, E. R. Sistemas políticos da Alta Birmânia. São Paulo: EDUSP, 1996, p 40.

TURATTI, M. C. M. Os filhos da lona preta: identidade e cotidiano em acampamentos do MST. São Paulo: Alameda, 2005. 


\section{MST'S ORGANIZATIONAL STRUCTURE: political logic and practical logic}

\author{
Roberto de Sousa Miranda \\ Luis Henrique Hermínio Cunha
}

Our aim is to understand the relationships between the base of the Landless Rural Workers Movement (MST) and their leaders, taking the structural organization formally adopted in 2003 as an element for mediation. For this purpose, three analytical keys are used: Clastres, who explores the idea of structure separate from social body; Leach, who opposes (contrasts) an abstract model of organization with the practical situations observed and interpreted from the perspective of the materiality of behavior of the settlers and squatters; Neo-institutionalism, which studies how institutions regulate social life through rules and norms. These analyses were based on observations made at the Twelfth MST Meeting in the State of Paraíba and at the rural settlements called José Antonio Eufrosino and Osiel Pereira, located in the municipality of Campina Grande. Rejecting approaches that attempt to measure how much the formal organizational models have been adopted by the social groups, we have tried to reveal the productive incongruences of the dynamics of MST's organizational restructuring.

KEY WORDS: MST. Organizational Structure. Rural Settlements. Paraíba.

\section{LA STRUCTURE ORGANISATIONNELLE DU MST: logique politique et logique pratique}

\author{
Roberto de Sousa Miranda \\ Luis Henrique Hermínio Cunha
}

Notre objectif est de comprendre les relations existantes entre la base du Mouvement des Travailleurs Ruraux Sans Terre (MST) et leurs dirigeants en prenant comme élément de médiation la structure organisationnelle formellement adoptée en 2003. Pour ce faire, nous utilisons trois clés analytiques: Clastres qui sonde l'idée de structure séparée du corps social; Leach qui oppose un modèle abstrait d'organisation aux situations pratiques observées et interprétées à partir de la matérialité du comportement de ceux qui ont reçu une parcelle de terre et de ceux qui campent; le Néoinstitutionnalisme qui considère les institutions en tant que règles et normes qui régulent la vie sociale. Les analyses se basent sur des observations faites lors du XIIe Rassemblement d'Etat du MST dans la Paraiba et dans les implantations rurales José Antonio Eufrosino et Osiel Pereira, situés dans la commune de Campina Grande. Rejetant les approches qui essaient de mesurer le degré d'adoption des modèles d'organisation formelle des groupes sociaux, nous tentons de révéler les incongruités productrices des dynamiques de restructuration de l'organisation du MST.

MotS-CLÉS: MST. Structure Organisationnelle. Implantations Rurales. Paraíba.

Roberto de Sousa Miranda - Graduado em Ciências Sociais (2005), Mestre em Sociologia (2007) e Doutor em Ciências Sociais (2011) pela Universidade Federal de Campina Grande. Professor da Unidade Acadêmica de Ciências e Tecnologia Ambiental da Universidade Federal de Campina Grande. Tem experiência em Sociologia Rural, especialmente na análise de instituições sociais e desempenho institucional em assentamentos rurais; e em Ecologia Política, com ênfase em conflitos e mudança ambiental no Cerrado e PréAmazônia maranhense.

Luis Henrique Hermínio Cunha - Graduado em Comunicação Social/Jornalismo pela Universidade Estadual da Paraíba (1994), Mestre em Sociologia Rural pela Universidade Federal da Paraíba (1997) e Doutor em Desenvolvimento Sustentável do Trópico Úmido pela Universidade Federal do Pará (2002). Atualmente é professor adjunto I da Universidade Federal de Campina Grande e Membro de corpo editorial da Revista Raízes, Revista de Ciências Sociais e Econômicas. Tem experiência na área de Sociologia, com ênfase em Sociologia Rural, atuando, principalmente, nos seguintes temas: arranjos institucionais, manejo comunitário, recursos comuns, Amazônia, mediadores e desenvolvimento rural sustentável. 
